\title{
Pseudoaneurysm after an ultrasound-guided breast core needle biopsy in a lactating woman
} \author{
Ana Paula de Carvalho Miranda Rosati Rocha ${ }^{4}$, Érica Endo5 \\ 1. Department of Breast Radiology, Fleury Group, Rio de Janeiro, Brazil \\ 2. Department of Breast Radiology, Hermes Pardini Group, Rio de Janeiro, Brazil \\ 3. Department of Radiology, Lagoa Federal Hospital, Rio de Janeiro, Brazil \\ 4. Department of Breast Radiology, Fleury Group, Rio de Janeiro, Brazil \\ 5. Department of Ultrasound, Fleury Group, São Paulo, Brazil
}

Juliana Pessoa de Souza Chamadoira ${ }^{1 *}$, Camila de Carvalho Figueiredo ${ }^{2}$, Giovana Ortiz D'Ávila ${ }^{3}$,
* Correspondence: Juliana Pessoa de Souza Chamadoira, Department of Breast Radiology, Fleury Group, 600 Bartolomeu Mitre Avenue, Leblon, Rio de Janeiro, RJ, 22793-260, Brazil (入jpessoachamadoira@gmail.com)

Radiology Case. 2021 Oct; 15(10):10-19 :: $\quad$ DOI: 10.3941/jrcr.v15i10.4223

\begin{abstract}
This is a case report of a lactating woman in her twenties diagnosed with a breast pseudoaneurysm following a 14-gauge ultrasound-guided core needle biopsy detected by a Color Doppler exam, and treated with surgery. Further discussion concerning the patient's symptoms, useful imaging modalities, and treatment options are included. Knowledge on this complication is crucial for the correct diagnosis and best management and treatment.
\end{abstract}

\section{CASE REPORT}

\section{CASE REPORT}

A twenty-nine-year-old female patient noticed a palpable and mobile mass on her left breast during the third month of lactation. A breast ultrasound (US) exam identified a solid, hypoechoic, oval, circumscribed, parallel mass and a color Doppler exam revealed internal vascularity and vessels in rim around the mass, measuring $2.6 \times 2.5 \times 1.5 \mathrm{~cm}$ in the upper inner quadrant (11 o'clock position, $3 \mathrm{~cm}$ from the nipple) of the left breast (Figure 1), most likely a benign-appearing fibroepithelial lesion, such as a fibroadenoma (FA).

Breast vascularity is substantially increased during pregnancy and lactation. Local procedures should, therefore, be carefully considered, and deferring them until after the breastfeeding period is often the most appropriate choice [1].
Additionally, emerging data suggest that short-interval followup is a reasonable option for lesions displaying benign characteristics [2]. In this case, given her high level of anxiety, the patient requested a breast biopsy during her lactation period. The case was discussed with a multidisciplinary team of radiologists, gynecologists, and breast surgeons, and the procedure was not deferred.

We, therefore, proceeded with tissue sampling for a definitive diagnosis. After obtaining an informed consent, an ultrasound-guided core needle biopsy (CNB) was performed with a 14-gauge needle and semi-automatic device, using a medial to lateral approach, targeting the solid mass at 11 o'clock position in the left breast. During the procedure, the patient developed an intense pulsating bleeding and subsequent hematoma (Figure 2). Manual compression and 
cold packs were applied for 20 minutes until hemostasis was achieved.

The follow-up was scheduled after one week and an ultrasound exam revealed noticeable hematoma reduction. However, a new circumscribed round saccular mass measuring $0.8 \times 0.8 \times 0.7 \mathrm{~cm}$ (Figure 3) displaying mixed echogenicity and a high-velocity blood flow was observed, demonstrating direct communication between the saccular and blood vessel lumen flows through a vascular neck, forming a yin-yang sign (Figure 4). The image was suggestive of a pseudoaneurysm and was located $2.1 \mathrm{~cm}$ away from the biopsy target mass (Figure 5).

The biopsy result revealed a biphasic neoplasm (fibroepithelial) suggestive of fibroadenoma with myxoid stroma. In consensus, both the breast surgeon and the patient decided for surgical excision of the mass and the vascular lesion. Two post-surgical specimen radiographs were provided, demonstrating that the wires and both lesions were excised with surrounding breast tissue (Figure 6).

\section{DISCUSSION}

\section{Etiology \& Demographics:}

Percutaneous breast biopsies have become widely used for breast lesion diagnosis. If a suspicious lesion has been identified on mammography or ultrasound, BI-RADS 4 or BIRADS 5 categories are assigned and tissue sampling is warranted, except in rare circumstances (e.g., if the patient presents comorbidities that would contraindicate biopsy). If a lesion fits all of the probably benign criteria (oval shape, circumscribed margins, and parallel orientation), it can confidently be classified as a BI-RADS 3 lesion, and short term follow-up is recommended [2]. However, image-guided core needle biopsy (CNB) may be performed after a complete imaging assessment if there are enough reasons to establish a definitive more immediate diagnosis. For example, BI-RADS 3 lesions in high-risk patients or in patients awaiting organ transplant, presenting known synchronous cancers, or attempting pregnancy may be appropriate candidates for tissue sampling. Situations in which biopsy may alleviate extreme patient anxiety may also prompt tissue sampling [3].

Although fine-needle aspiration (FNA) can be a diagnostic alternative for an ACR-BIRADS Category 3 assessment, we based our management for this case on a larger series that demonstrates that CNB is superior to FNA in terms of sensitivity, specificity, and correct histological grading of palpable masses $[3,4]$.

Complications arising from $\mathrm{CNB}$ are infrequent and, usually, not clinically significant. The most common complication is bleeding, which is usually easy to control during the procedure, followed by hematoma development. However, rarer complications such as infection, fistulas and pseudoaneurysm may sometimes occur $[5,6,7]$. In breastfeeding patients, the rate of complications is expected to be higher. Expectedly, bleeding is slightly more frequent due to vascular growth, and infections more common due to the presence of milk, which acts as a culture media for microbial overgrowth. Milk fistula may occur, although rarely, consisting of milk discharge from a breast or axillary skin breach, originating from a track between a milk duct and skin surface [8].

Breast pseudoaneurysms are an uncommon complication, caused by the transmural rupture of an arterial wall and subsequent hematoma formation. This occurs when the blood leaks from an open site in the arterial wall track through adjacent tissues, ending in a saccular collection called a pseudoaneurysm [5,6]. Unlike a true aneurysm, pseudoaneurysms lack the three vessel wall layers (intima, media, and adventitia) and are contained by perivascular tissue $[7,9]$.

The literature concerning this event is scarce and indicates a low incidence $[10,11]$, although no studies report specific breast pseudoaneurysm percentages. A comprehensive search of the literature obtained 23 cases reported in the literature during the last 22 years.

Reported risk factors for breast pseudoaneurysms include arteriosclerosis, advanced age (over 50 years old), being female and anticoagulant therapy [12]. Increased vascularity and vascular permeability during pregnancy and lactation may act as risk factors for local complications of percutaneous procedures.

Most breast pseudoaneurysms occur as a result of trauma, surgery, local infection or diagnostic procedures, such as core needle biopsies [6]. However, spontaneous pseudoaneurysm occurrence has been previously reported and is more likely to occur in patients presenting hypertensive disease, underlying atherosclerotic disease and those taking anticoagulation medication $[7,13]$. The patient presented herein exhibited no previous medical history in this regard, including no coagulation disorders, anticoagulation therapy or systemic diseases. Breast hypervascularity during lactation was the only identifiable predisposing factor.

\section{Clinical \& Imaging findings:}

Clinically, pseudoaneurysms can manifest as palpable and pulsating masses at the biopsy site, in general between 1 to 3 $\mathrm{cm}$, and can appear either immediately after the biopsy or from weeks to months after the procedure [13].

Color Doppler ultrasound exams are a first-line investigation method for pseudoaneurysm diagnosis, reaching an accuracy of up to $95 \%[10,14,15]$.

Breast pseudoaneurysms present as a mixed echogenicity circumscribed mass on ultrasound, with a thick wall adjacent to the biopsy/trauma area. They can be misinterpreted as a suspicious complex solid and cystic mass in B-mode but are clearly observed as connected to an artery when analyzed by Color Doppler exams, with a turbulent internal flow and displaying typical yin-yang sign [10]. However, the typical vascular nature revealed by a Doppler exam associated to a history of recent trauma and hematoma formation should direct the examiner to this diagnosis. 
Other imaging modality methods are usually not required for diagnosis. Given the high level of experience of the radiologists involved in the present case, a Color Doppler ultrasound was sufficient for diagnosis, so no images from other methods are available for illustration. However, based on literature findings, it is noteworthy that, pseudoaneurysm appearance on mammography exhibits an equal density, round, and circumscribed mass near a vessel, resembling an intramammary lymph node [13, 16]. On Magnetic Resonance Imaging (MRI), they appear as round and circumscribed masses, hyperintense in $\mathrm{T} 1$ weighted images (indicating hematic content) and in $\mathrm{T} 2$ weighted images, with contrast enhancement and located near vessels, resembling intramammary lymph nodes $[14,16]$. On Computed Tomography Angiography (CTA), they appear as masses with central contrast enhancement, hypoattenuating (non-contrast) or hyperattenuating (contrast-enhanced) and presenting smooth-walled sacs adjacent to an artery, usually displaying communication [17].

\section{Treatment \& Prognosis:}

Fibroadenomas diagnosed by CNB with imaging pathologic concordance may usually be safely managed without the need for surgical procedures [18]. However, the diagnosis of benign disease including fibroadenoma or fibroepithelial lesions can sometimes prove a management challenge for a multidisciplinary breast team within the current diagnostic paradigm, especially given the lack of adequate evidence guiding the need for excision. Some institutions currently manage clinically, radiologically, and pathologically concordant presumptive fibroadenomas larger than $3 \mathrm{~cm}$ by excision, due to the postulated risk of underlying in situ ductal carcinomas (DCIS) or phyllodes tumors (PT), particularly in the case of larger lesions. At present, despite many useful histologic indicators, there are no absolutely determinant features able to distinguish between FA and benign PT in CNBs, resulting in a high number of excisions to rule out this kind of lesion [19].

In addition, some patients may prefer FA removal for cosmetic reasons, due to discomfort, or the desire for diagnostic certainty. In the case reported herein, the patient evolved in consensus with the breast surgeon favorably to surgical management.

Regarding breast pseudoaneurysm management, conservative treatments can be attempted first, such as ultrasound-guided vascular mass compression, which may be repeated with periodic lesion monitoring. Many breast pseudoaneurysm cases undergo spontaneous thrombosis and are not clinically evident [20]. Alternatively, or as a next step, thrombosing with gelatin particles (Gelfoam, Upjohn), glue particles, or coil or alcohol injections, as well as endovascular treatment can be employed, with the final alternative being a surgical procedure $[10,15,20]$.

Due to their fragile walls, most pseudoaneurysms are at risk of rupture. Although some physicians prefer close observation [15], especially in the case of small and asymptomatic lesions, there is no way to predict which pseudoaneurysms will undergo spontaneous thrombosis.
Therefore, and most of the time, interventional treatment is required [21].

\section{Differential Diagnoses:}

\section{Breast aneurysm:}

Rarer than pseudoaneurysms, breast aneurysms result from abnormal dilatations of all three arterial wall layers. They are thought to be caused by prior trauma, while pseudoaneurysms can result also from spontaneous hemorrhage due to coagulopathies or uncontrolled hypertension, or due to vascular invasion by breast malignancy. Clinically, a slowly enlarging pulsatile mass can be present [22]. Like pseudoaneurysms, true breast aneurysms are well studied by US examination, consisting of anechoic, well-defined cystic structures containing moving contents. A Color Doppler exam may indicate vascularity with a turbulent flow. Their mammography appearance is the same as pseudoaneurysms, of an equal density, circumscribed mass, close to vessels that can simulate an intramammary lymph node. In MRIs, T1 weighted images may indicate a flow void within an aneurysmal sac secondary to turbulence or heterogeneous signal intensity, while T2 weighted images will display a typically hypointense signal. In CTAs, brilliant contrast enhancement within these lesions are observed, similar to an adjacent vessel.

\section{Hematoma:}

Hematomas comprise the second most common breast biopsy complication after bleeding. In US examinations, following the hyperechoic acute phase, hematomas develop into a predominantly anechoic heterogeneous collection that may contain fluid (complex solid and cystic mass). Unlike pseudoaneurysms, hematomas do not present internal vascularity when evaluated by Doppler exams and tend to disappear or degenerate into fat necrosis [13]. In mammographies, they appear as a developing asymmetry in and around the biopsy site. Less frequently, they can appear as a new oval or irregular mass at the biopsy site and calcifications may develop in later stages. MRI findings are variable, depending on the hematoma time frame. Hematomas are hyperintense in $\mathrm{T} 1$ weighted images during earlier stages, and hypointense in $\mathrm{T} 2$ weighted images and display no enhancement. In CTAs, well-circumscribed high-density fluid attenuation masses are observed.

\section{Oil cyst:}

Oil cysts are a distinctive form of fat necrosis in which a macroscopic pool of oil develops, rimmed by a thin membrane [23]. They are usually associated with previous breast injuries, including breast biopsies. In US assessments, most oil cysts present as cystic lesions containing echogenic lipid masses. If rim calcifications are present, a posterior acoustic shadowing may be observed. In Color Doppler exams, no vascular flow is detected. The differential diagnosis between oil cysts and other solid and cystic lesions can be difficult to establish by ultrasound examination. However, typical oil cyst imaging aspects on mammographies can conclude the diagnosis without additional investigation, as these cysts appear as oval or round circumscribed masses containing fat and pseudocapsules that can calcify (rim calcification). In MRI examinations, round and oval masses in which the center presents a fat sign in all weightings is noted with the amount 
of acute and chronic inflammatory changes. A decreased signal in T2-weighted, fat-suppressed images and a high signal in T2- and T1-weighted, non-fat-suppressed images are noted. Most oil cysts demonstrate no enhancement, although a thin enhancing rim may be apparent in some patients. In CTAs, well-circumscribed non-enhancing and fat-containing masses are observed, and wall calcification may or may not be present.

\section{Conclusion:}

Breast pseudoaneurysms comprise an extremely rare complication following percutaneous breast biopsies. This type of lesion should be evaluated by Color Doppler ultrasound examination for diagnosis confirmation, in which the blood flow is characterized by a typical swirling motion, termed "the yin-yang sign". Some complex solid and cystic lesions can mimic breast pseudoaneurysms, including true aneurysms, hematomas and oil cysts. Conservative treatments can be attempted as a first step, but endovascular procedures or surgical lesion resection may be required. Lactation is associated with markedly increased breast vascularity and vascular permeability, which may play a role as a risk factor for the development of this rare complication.

\section{TEACHING POINT}

When radiologists face a breast lesion exhibiting mixed echogenicity in ultrasound exams in an area subject to previous trauma with subsequent hematoma formation, the possibility of a pseudoaneurysm should be raised and a Color Doppler study is required. This exam will indicate the typical vascular nature of the lesion and a diagnosis can be established without further investigation.

\section{REFERENCES}

1. Pesce K, Chico MJ, Binder F. Breast pseudoaneurysm after core needle biopsy in a pregnant patient. Radiol Case Rep. 2020 Oct 29;16(1):35-39. PMID: 33163130.

2. Raza S, Goldkamp AL, Chikarmane SA, Birdwell RL. US of breast masses categorized as BI-RADS 3, 4 and 5: pictorial review of factors influencing clinical management. Radiographics. 2010 Sep; 30(5):1199-213. PMID: 20833845.

3. Moy L, Heller SL, Bailey L, et al. ACR Appropriateness Criteria Palpable Breast Masses. J Am Coll Radiol. 2017 May; 14 (5S): S203-S224. PMID: 28473077.

4. Brancato B, Crocetti E, Bianchi S, et al. Accuracy of needle biopsy of breast lesions visible on ultrasound: audit of fine needle versus core needle biopsy in 3233 consecutive samplings with ascertained outcomes. Breast. 2012 Aug;21(4):449-54. PMID: 22088803.

5. Bitencourt AGV, Cohen MP, Graziano L, et al. Pseudoaneurysm after Ultrasound-Guided Vacuum-Assisted Core Breast Biopsy. The Breast Journal, Mar-Apr 2012; 18(2):177-8. PMID: 22211950.
6. Wilkes AN, Needleman L, Rosenberg AL. Pseudoaneurysm of the Breast. American Journal of Roentgenology (AJR), 1996 Sep;167(3):625-61996. PMID: 8751665.

7. Dixon A, Enion D. Pseudoaneurysm of the breast: Case study and review of literature. The British Journal of Radiology, 2004 Aug; 77(920):694-7. PMID: 15326053.

8. Alipour S.Local Complications of Breast Surgery during Pregnancy and Lactation. Adv Exp Med Biol. 2020; 1252: 101-105. PMID: 32816268.

9. El Khoury M, Mesurolle B, Kao E, Mujoomdar A, Tremblay F. Spontaneous Thrombosis of Pseudoaneurysm of the Breast Related to Core Biopsy. American Journal of Roentgenology (AJR), 2007 Dec; 189(6):W309-11. PMID: 18029840 .

10. Samper AMC, Gonzalez HM, Arias IA, Sierra DS, Dominguez BM, Ayet CF. A case report of pseudoaneurysm after a core needle biopsy of breast cancer. The Breast Journal, 2020 Feb; 26(2):252-254. PMID: 31486171.

11. Farrokh D, Fallah-Rastegar Y, Abbasi B. Pseudoaneurysm of the breast after core needle biopsy: Successful treatment with focused ultrasound-guided compression. The Breast Journal, 2019 Mar; 25(2):312-313. PMID: 30790385.

12. Sasada S, Matsubayashi HN, Yokoyama G, et al. Case report of pseudoaneurysm caused by core needle biopsy of the breast. Breast Cancer, 2010; 17(1):75-8. PMID: 19277831.

13. Mahoney MC, Ingram AD. Breast Emergencies: Types, Imaging Features, and Management. American Journal of Roentgenology (AJR), 2014 Apr; 202(4):W390-9. PMID: 24660738 .

14. Bazzocchi M, Francescutti GE, Zuiani C, Frate CD, Londero V. Breast Pseudoaneurysm in a Woman After Core Biopsy: Percutaneous Treatment with Alcohol. American Journal of Roentgenology (AJR), 2002 Sep; 179(3):696-8. PMID: 12185048.

15. Russell T, Creagh-Barry M. Breast pseudoaneurysm arising from core needle biopsy should be left well alone. BMJ Case Report, 2017 Sep 28; 2017:bcr2017221546. PMID: 28963117.

16. Erdil I, Dursun M, Salmaslioglu A, Ozcinar B, Acunas G. Pseudoaneurysm in the Breast after Core Biopsy: Doppler US and MRI Findings. The Breast Journal, Jul-Aug 2010; 16(4):427-9. PMID: 20545941.

17. Saad NEA, Saad EAW, Davies GM, Waldman DL, Fultz PJ, Rubens DJ. Pseudoaneurysms and the Role of Minimally Invasive Techniques in Their Management. Radiographics. 2005 Oct; 25 Suppl 1:S173-89. PMID: 16227490.

18. Osdol AD Van, Landercasper J, Andersen JJ, et al. Determining whether excision of all fibroepithelial lesions of the breast is needed to exclude phyllodes tumor: upgrade rate of fibroepithelial lesions of the breast to phyllodes tumor. JAMA Surg. 2014 Oct; 149(10):1081-5. PMID: 25162470. 
19. Neville G, O'Neill C, Murphy R, et al. Is excision biopsy of fibroadenomas based solely on size criteria warranted?. Breast J. 2018 Nov; 24(6):981-985. PMID: 29802656.

20. Filho ARR, Machado AF, Vieira SC, Dantas ARGNT. Pseudoaneurysm of the breast. Breast Disease, 2015; 35(2):149-52. PMID: 25352275.

21. Saad NEA, Saad WEA, Davies MG, Waldman DL, Fultz PJ, Rubens DJ. Pseudoaneurysms and the Role of Minimally Invasive Techniques in Their Management. RadioGraphics 2005 Oct; 25 Suppl 1: S173-89. PMID: 16227490.
22. Jesinger RA, Lattin Jr GE, Ballard EA, Zelasko EA, Glassman LM. Vascular Abnormalities of the Breast: Arterial and Venous Disorders, Vascular Masses, and Mimic Lesions with RadiologicPathologic Correlation. Radiographics, NovDec 2011; 31(7):E117-36. PMID: 22084191.

23. Harvey JA, Moran RE, Maurer EJ, DeAngelis GA. Sonographic Features of Mammary Oil Cysts. J Ultrasound Med. 1997 Nov; 16(11):719-24. PMID: 9360234.

\section{FIGURES}

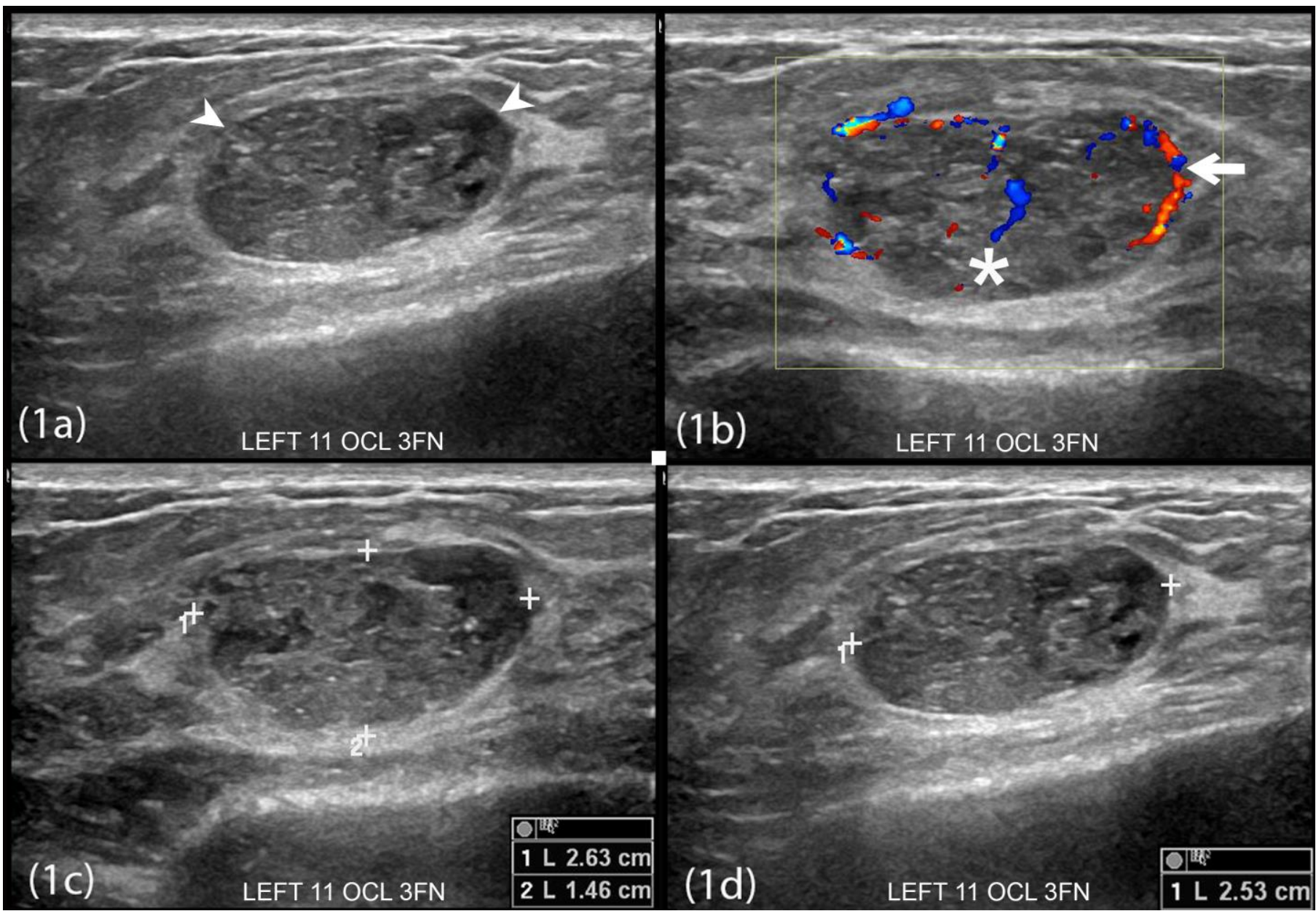

Figure 1: 29-year-old lactating female with a palpable solid mass at 11 o'clock position, $3 \mathrm{~cm}$ from the nipple in the left breast.

FINDINGS: (1a) Grayscale breast ultrasound indicating a solid, hypoechoic, oval, circumscribed and parallel mass (arrowheads). (1b) A Color Doppler ultrasound demonstrated the mass with internal vascularity (asterisk) and vessels in rim surrounding the mass (arrow). (1c) Mass measuring $2.6 \times 1.5 \mathrm{~cm}$ (between calipers) in the transverse plane. (1d) Mass measuring $2.5 \mathrm{~cm}$ (between calipers) in the sagittal plane.

TECHNIQUE: GE Logic E9 ultrasound. ML6 - 15 MHz linear probe. 


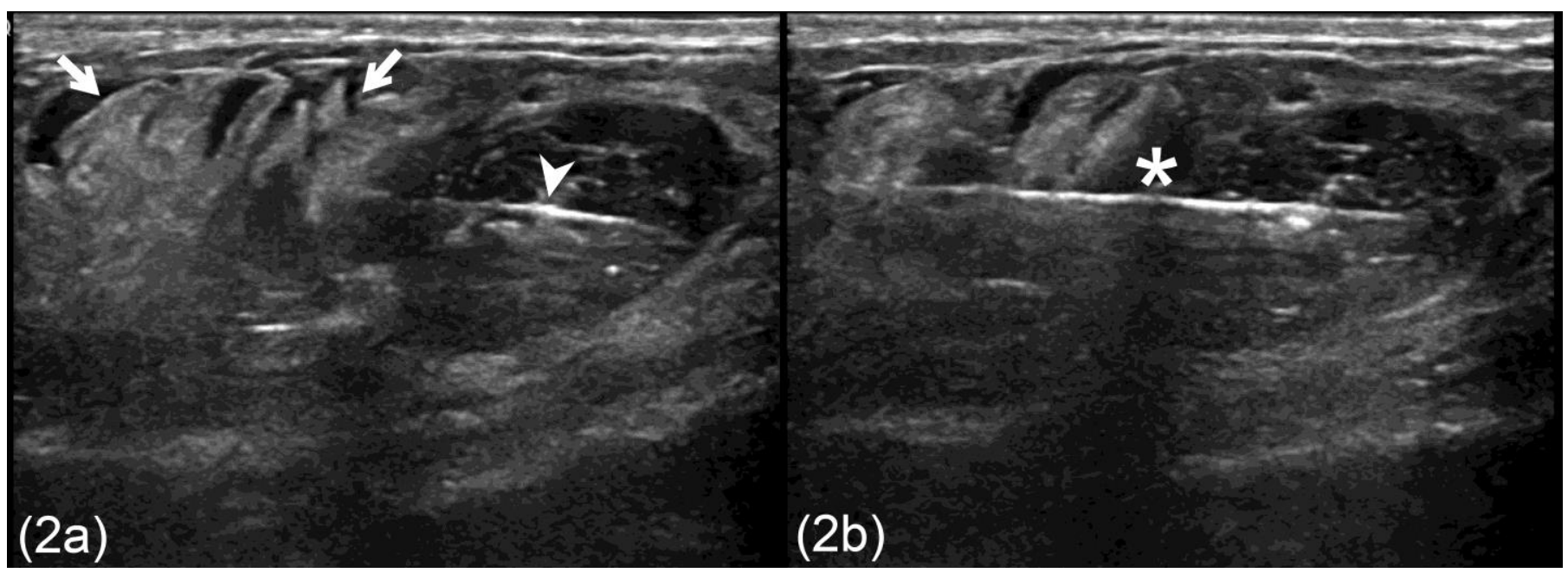

Figure 2: 29-year-old lactating female with a palpable solid breast mass at the left upper inner quadrant during an ultrasoundguided 14-Gauge core needle biopsy.

FINDINGS: (2a) Grayscale breast ultrasound indicating the development of a hyperechogenic area next to the target mass, suggesting a hematoma (arrows) during a 14-gauge core needle biopsy. Needle in the sagittal plane (arrowhead) targeting the solid mass. (2b) Needle in the transverse plane (asterisk) targeting the solid mass.

TECHNIQUE: GE Logic E9 ultrasound. ML6 - 15 MHz linear probe.

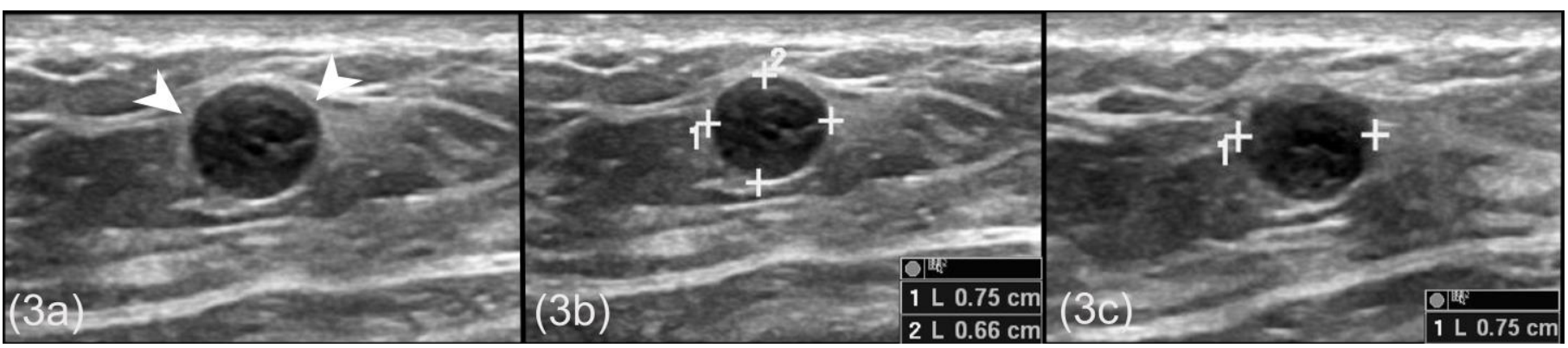

Figure 3: 29-year-old lactating female with a circumscribed round saccular mass characterized by mixed echogenicity at the left upper inner quadrant suggesting pseudoaneurysm after an ultrasound-guided 14-Gauge core needle biopsy.

FINDINGS: (3a) Grayscale breast ultrasound indicating a round mass with mixed echogenicity (arrowheads). (3b) Mass measuring $0.8 \times 0.7 \mathrm{~cm}$ (between calipers) in the transverse plane. (3c) Mass measuring $0.8 \mathrm{~cm}$ (between calipers) in the sagittal plane.

TECHNIQUE: GE Logic E9 ultrasound. ML6 - 15 MHz linear probe. 


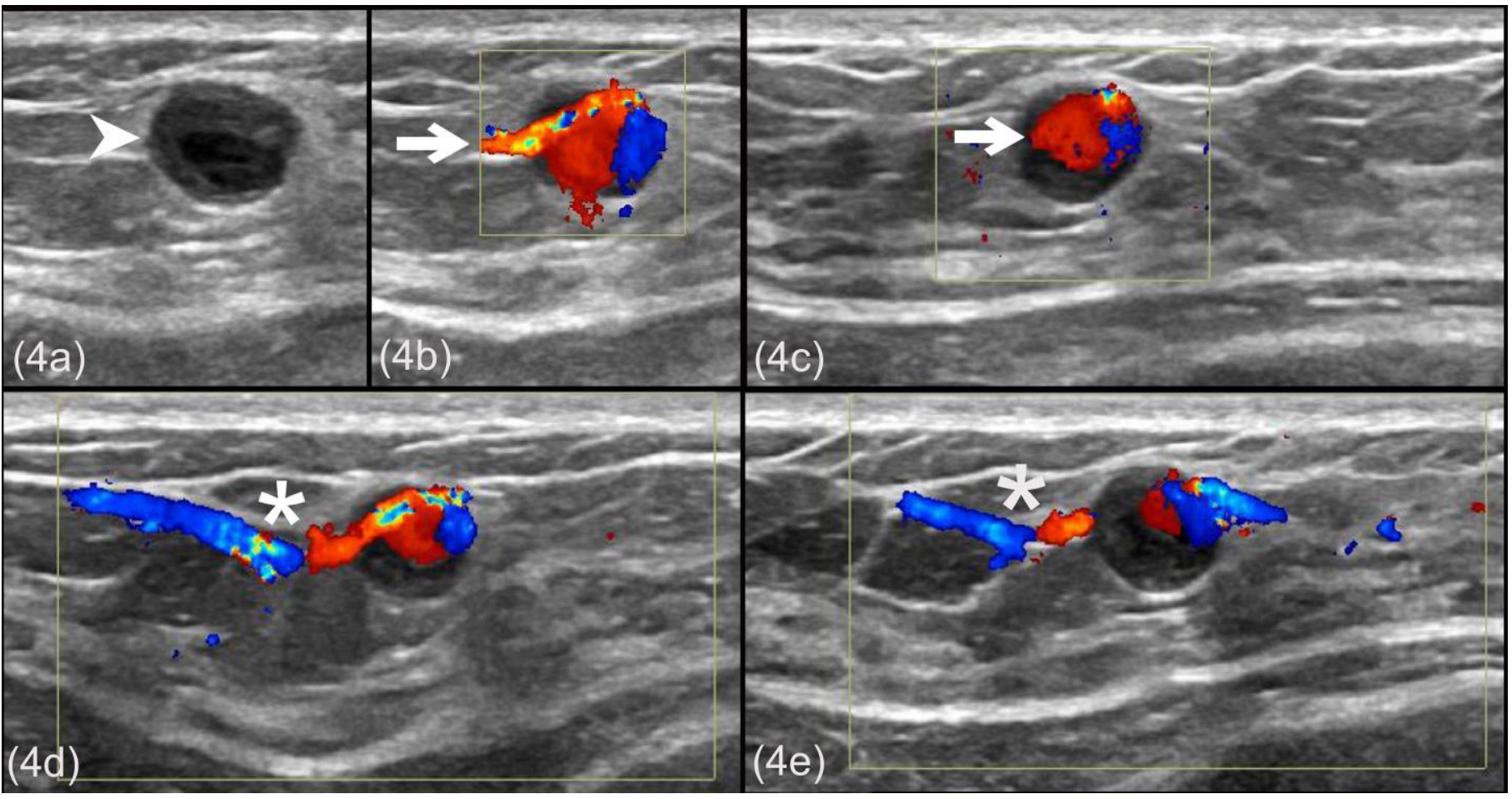

Figure 4: 29-year-old lactating female presenting a breast pseudoaneurysm after a 14-Gauge core needle biopsy.

FINDINGS: (4a) Grayscale breast ultrasound indicates a round mass with mixed echogenicity (arrowhead). (4b) and (4c) A Color Doppler study demonstrates the typical yin-yang sign (arrows). (4d) and (4e) Flow communication between the saccular lumen and the blood vessel lumen through a vascular neck (asterisk).

TECHNIQUE: GE Logic E9 ultrasound. ML6 - 15 MHz linear probe.

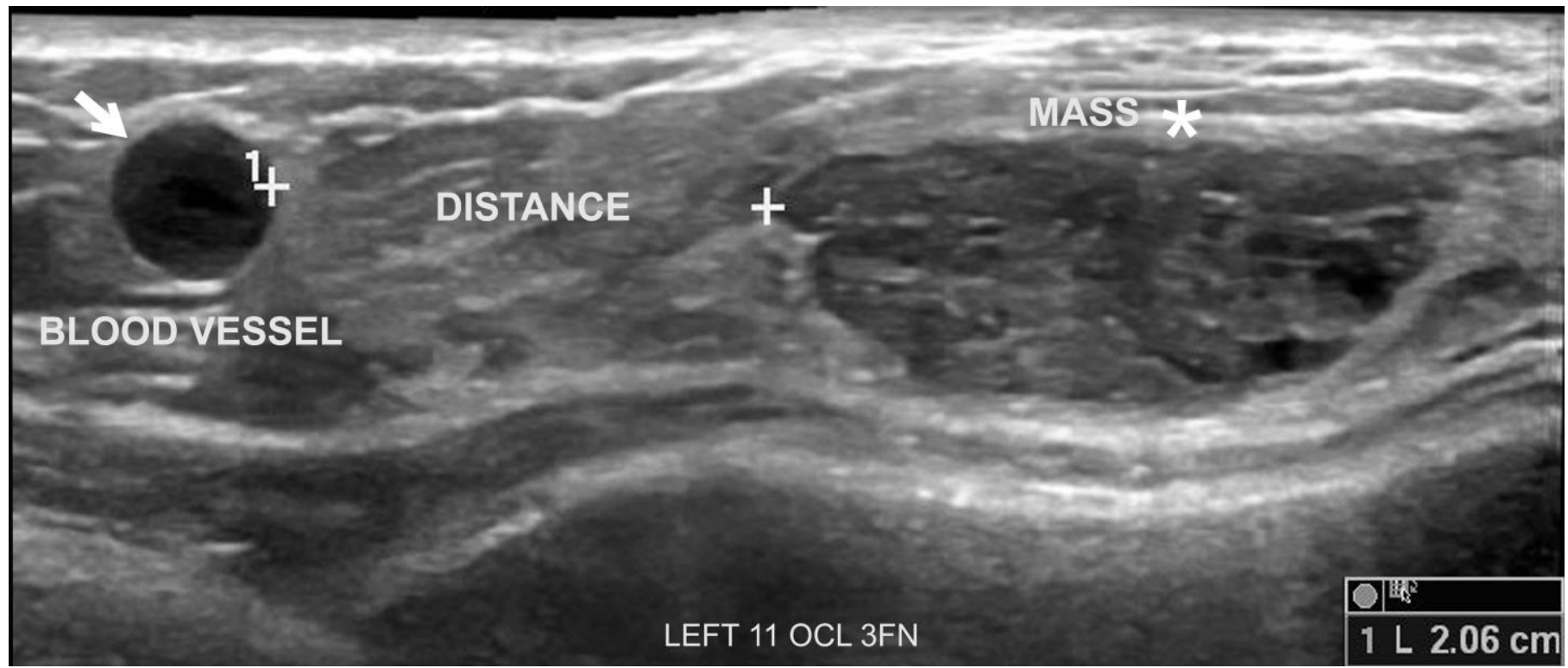

Figure 5: 29-year-old lactating female presenting a breast pseudoaneurysm after a 14-Gauge needle core biopsy.

FINDINGS: Panoramic imaging ultrasound indicating a well-defined round saccular mass (arrow) $2.1 \mathrm{~cm}$ away (calipers) from the biopsy target mass (asterisk).

TECHNIQUE: GE Logic E9 ultrasound. ML6 - 15 MHz linear probe. 


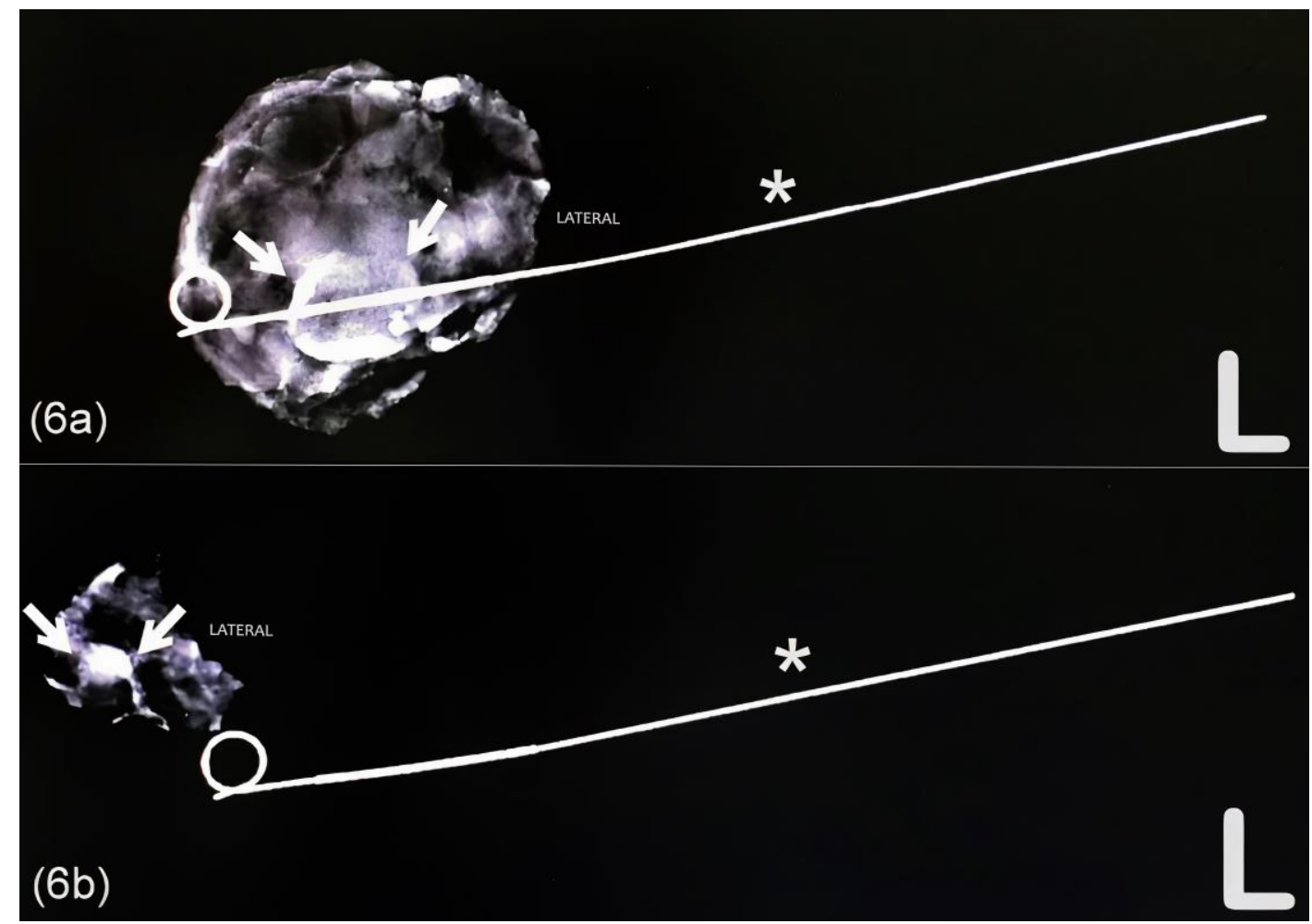

Figure 6: 29-year-old lactating female who underwent wire-guided surgical excision of a biopsy-proven fibroepithelial lesion in the left breast and a post-biopsy pseudoaneurysm which developed in the vicinity. Two postoperative specimen radiographs were provided.

FINDINGS: (6a) A postoperative specimen radiograph single 2-D image of the left breast, demonstrating that the wire (asterisk) placed before surgery and the mass (arrows) (biopsy-proven fibroepithelial lesion) were excised with surrounding breast tissue. (6b) A postoperative specimen radiograph single 2-D image of the left breast demonstrating that the wire (asterisk) placed before the surgery and a small centred high-density oval mass (arrows) (post-biopsy pseudoaneurysm) were excised with surrounding breast tissue.

TECHNIQUE: BioVision Faxitron ${ }^{\circledR}$ Digital Surgical Specimen Radiography System - Geometric Magnification: 1,5X. Tube current - $1.5 \mathrm{~mA}$

\begin{tabular}{|l|l|}
\hline Etiology & Mostly after breast trauma, biopsy, or surgery and, sometimes, spontaneous. \\
\hline Incidence & Low, of about 23 reported cases in literature. \\
\hline Gender ratio & Female. \\
\hline Age Predilection & Over 50 years old. \\
\hline Risk factors & $\begin{array}{l}\text { - Arteriosclerosis. } \\
\text { - Advanced age. } \\
\text { - Being female. } \\
\text { - Anticoagulant therapy. }\end{array}$ \\
\hline Treatment & $\begin{array}{l}\text { - Ultrasound-guided vascular mass compression. } \\
\text { - Thrombosing, or alcohol injections, endovascular treatment. } \\
\text { - Surgical procedure. }\end{array}$ \\
\hline Prognosis & $\begin{array}{l}\text { Some pseudoaneurysms may thrombose spontaneously, and others, as in the case reported herein, may require thrombosis } \\
\text { intervention. }\end{array}$ \\
\hline Imaging findings & $\begin{array}{l}\text { Ultrasound: is the best diagnosis method, where the lesion appears as a mixed echogenicity circumscribed mass, with a } \\
\text { thick wall, adjacent to a hematoma area, clearly connected to an artery as observed in a Color Doppler exam and with a } \\
\text { turbulent internal flow, displaying the typical yin-yang sign. } \\
\text { - Mammography: the lesion appears as an equal-density, round, and circumscribed mass, near a vessel, resembling an } \\
\text { intramammary lymph node. } \\
\text { - CTA: mass with a central contrast enhancement, hypoattenuating (non-contrast) or hyperattenuating (contrast-enhanced) } \\
\text { smooth-walled sac adjacent to an artery, usually displaying a communication. } \\
\text { - MRI: round and circumscribed mass, hyperintense in T1 weighted images (indicating hematic content) and in T2 } \\
\text { weighted images, with contrast enhancement, near a vessel, resembling an intramammary lymph node. }\end{array}$ \\
\hline
\end{tabular}

Table 1: Summary table of breast pseudoaneurysm. 


\begin{tabular}{|c|c|c|c|c|}
\hline & Ultrasound & Mammography & CTA & MRI \\
\hline $\begin{array}{l}\text { Breast } \\
\text { pseudoaneurymsm }\end{array}$ & $\begin{array}{l}\text { The best method for diagnosis: } \\
\text { - Mixed echogenicity } \\
\text { circumscribed mass, with a } \\
\text { thick wall. } \\
\text { - Adjacent to a hematoma area. } \\
\text { - Clearly connected to an } \\
\text { artery at Color Doppler } \\
\text { exam. } \\
\text { - Turbulent internal flow, with } \\
\text { the typical sign of yin-yang } \\
\text { observed by a Color Doppler } \\
\text { exam. }\end{array}$ & $\begin{array}{l}\text { - Equal density, round } \\
\text { and circumscribed } \\
\text { mass. } \\
\text { - Near a vessel, } \\
\text { resembling an } \\
\text { intramammary lymph } \\
\text { node. }\end{array}$ & $\begin{array}{l}\text { - Mass displaying a central } \\
\text { contrast enhancement. } \\
\text { - Hypoattenuating (non- } \\
\text { contrast) or } \\
\text { hyperattenuating } \\
\text { contrast-enhanced) } \\
\text { smooth-walled sac } \\
\text { adjacent to an artery, } \\
\text { usually with a } \\
\text { communication. }\end{array}$ & $\begin{array}{l}\text { - Round and circumscribed } \\
\text { mass. } \\
\text { - Hyperintense in T1 } \\
\text { weighted image (indicating } \\
\text { hematic content) and in T2 } \\
\text { weighted images. } \\
\text { - With contrast } \\
\text { enhancement. } \\
\text { - Near a vessel, resembling } \\
\text { an intramammary lymph } \\
\text { node. }\end{array}$ \\
\hline Breast aneurysm & $\begin{array}{l}\text { - Rare. } \\
\text { - Occurs post-trauma. } \\
\text { anechoic well-defined cystic } \\
\text { structure containing moving } \\
\text { contents. } \\
\text { - Color Doppler exams may } \\
\text { reveal vascularity with a } \\
\text { turbulent flow. }\end{array}$ & $\begin{array}{l}\text { Exhibits the same } \\
\text { characteristics as } \\
\text { pseudoaneurysms. } \\
\text { Equal density, } \\
\text { circumscribed mass. } \\
\text { - Close to a vessel, which } \\
\text { can simulate an } \\
\text { intramammary lymph } \\
\text { node. }\end{array}$ & $\begin{array}{l}\text { - A brilliant contrast } \\
\text { enhancement is noted } \\
\text { within the lesion, similar } \\
\text { to an adjacent vessel. }\end{array}$ & $\begin{array}{l}\text { - T1 weighted images will } \\
\text { indicate a flow void within } \\
\text { an aneurysmal sac } \\
\text { secondary to turbulence or } \\
\text { a heterogeneous signal } \\
\text { intensity. } \\
\text { - T2 weighted images will } \\
\text { indicate a typically } \\
\text { hypointense signal. }\end{array}$ \\
\hline Hematoma & $\begin{array}{l}\text { - May appear as a hypoechoic } \\
\text { fluid collection or as a } \\
\text { complex, heterogeneous } \\
\text { cystic and solid mass. } \\
\text { - Usually displaying no } \\
\text { vascularity in Color Doppler } \\
\text { exams. }\end{array}$ & $\begin{array}{l}\text { - Appears as a } \\
\text { developing asymmetry } \\
\text { in and around the } \\
\text { biopsy site. } \\
\text { - Appears less frequently } \\
\text { as a new oval or } \\
\text { irregular mass at the } \\
\text { biopsy site. } \\
\text { - Calcifications may } \\
\text { develop in later stages. }\end{array}$ & $\begin{array}{l}\text { - A well-circumscribed } \\
\text { high-density fluid } \\
\text { attenuation mass. }\end{array}$ & $\begin{array}{l}\text { - MRI findings are variable, } \\
\text { depending on the time } \\
\text { frame of the hematoma. In } \\
\text { earlier stages: } \\
\text { - Hyperintense in T1 } \\
\text { weighted images. } \\
\text { - Hypointense in T2 } \\
\text { weighted images. } \\
\text { - No enhancement. }\end{array}$ \\
\hline Oil cyst & $\begin{array}{l}\text { - Cystic lesion containing } \\
\text { echogenic lipid masses. } \\
\text { - Posterior acoustic shadowing } \\
\text { if wall calcifications are } \\
\text { present. } \\
\text { - No vascular flow is detected } \\
\text { in Color Doppler exams. }\end{array}$ & $\begin{array}{l}\text { - Pathognomonic: oval or } \\
\text { round circumscribed } \\
\text { mass, containing fat and } \\
\text { pseudocapsules that can } \\
\text { calcify (rim } \\
\text { calcification). }\end{array}$ & $\begin{array}{l}\text { - Reassembly of } \\
\text { mammography findings: } \\
\text { a well-circumscribed } \\
\text { non-enhancing and fat- } \\
\text { containing mass, wall } \\
\text { calcification may or may } \\
\text { not be present. }\end{array}$ & $\begin{array}{l}\text { - A round and oval mass in } \\
\text { which the center presents a } \\
\text { fat sign in all weighings, } \\
\text { with the proportion of acute } \\
\text { and chronic inflammatory } \\
\text { changes. } \\
\text { - Exhibits a decreased signal } \\
\text { in T2-weighted, fat- } \\
\text { suppressed images and a } \\
\text { high signal on T2- and T1- } \\
\text { weighted, non-fat- } \\
\text { suppressed images. Most } \\
\text { oil cysts demonstrate no } \\
\text { enhancement although, a } \\
\text { thin enhancing rim may be } \\
\text { apparent in some patients. }\end{array}$ \\
\hline
\end{tabular}

Table 2: Differential diagnosis table for breast pseudoaneurysm. 


\section{ABBREVIATIONS}

$\mathrm{CNB}=$ Core needle biopsy

$\mathrm{CTA}=$ Computed Tomography Angiography

FA $=$ Fibroadenoma

FNA $=$ Fine needle aspiration

MRI $=$ Magnetic Resonance Imaging

PT $=$ Phyllodes Tumor

US = Ultrasound

\section{KEYWORDS}

Pseudoaneurysm; breast; ultrasound; core needle biopsy; complication

\section{Online access}

This publication is online available at:

www.radiologycases.com/index.php/radiologycases/article/view/4223

\section{Peer discussion}

Discuss this manuscript in our protected discussion forum at: www.radiolopolis.com/forums/JRCR

\section{Interactivity}

This publication is available as an interactive article with scroll, window/level, magnify and more features.

Available online at www.RadiologyCases.com

\section{Published by EduRad}

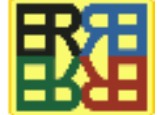

www.EduRad.org 